\title{
Antidepressants and liver disease
}

\author{
M. HILARY MORGAN AND A. E. READ \\ From the Department of Medicine, University of Bristol, at Bristol Royal Infirmary
}

SUMMARY Patients with cirrhosis were found to be extremely sensitive to tranylcypromine, and the use of this drug for the treatment of depression in such patients is contraindicated. Amitriptyline has a wider margin of safety in such patients, but caution is necessary when the higher therapeutic doses are prescribed.

Some patients with cirrhosis have been found to be extremely sensitive to the administration of certain drugs, for example powerful sedatives may induce coma or stupor (Laidlaw, Read, and Sherlock, 1961), and phenothiazines such as chlorpromazine may produce marked drowsiness (Read, Laidlaw, and McCarthy, 1969). This sensitivity can produce difficulties in the clinical management of such patients. Chronic depressive symptoms are not uncommon in the long, protracted illness accompanying hepatic cirrhosis, and depression may also be mimicked by the mental slowing and somnolence of complicating hepatic encephalopathy. For these reasons antidepressant drugs may not infrequently be given to cirrhotic patients. It therefore seemed important to assess the tolerance of the cirrhotic patient towards antidepressant drugs, so that their safety could be judged. Further impetus was given to the study by the known pharmacological action of monoamine oxidase inhibitors in diminishing the breakdown of amines to aldehyde and ammonia. This raised the possibility that the use of such a drug for the treatment of depression in cirrhotic patients could also produce an associated improvement in symptoms due to hepatic encephalopathy. Dawson and Sherlock in 1958 gave the mono-amine oxidase inhibitor isopropyl isonicitinyl hydrazide (Marsilid) to patients with liver disease, and reported a reduction in the blood ammonia levels of the patients who had an initially high fasting level. In the present study the mono-amine oxidase inhibitor tranylcypromine (Parnate) was selected for investigation, as one of the non-hydrazine derivatives in this group of drugs. No hydrazine derivative was included because of the known hepatotoxic effects of such substances (Sherlock, 1964). Amitriptyline (Tryptizol) was chosen as a commonly prescribed repre-

Received for publication 28 June 1972. sentative member of the group of tricyclic antidepressant drugs.

\section{Methods and Material}

\section{PATIENTS STUDIED}

A total of 32 patients with cirrhosis and 19 volunteer control subjects were investigated. The diagnosis of hepatic cirrhosis had been established in every case by liver biopsy. Ten patients and seven control subjects received tranylcypromine, administered orally as $10 \mathrm{mg}$ tablets, to a total dose of $80 \mathrm{mg}$ over the course of four days, while a further 12 patients and 12 control subjects were given amitriptyline orally, as $10 \mathrm{mg}$ tablets, to a total dose of $60 \mathrm{mg}$ over four days. A further five patients with cirrhosis received amitriptyline $25 \mathrm{mg}$ three times a day for seven days. Nine of the patients with cirrhosis had experienced previous episodes of hepatic encephalopathy, of whom five were included in the group receiving tranylcypromine (group A) and four in the group receiving amitriptyline. The five patients receiving tranylcypromine who gave no such history were designated group B. The prescribed doses of tranylcypromine and the week's course of amitriptyline were within the theropeutic range, but the shorter course of amitriptyline was at a lower dose level. Care was taken to exclude tyraminecontaining compounds from the diet while patients receiving tranylcypromine (Blackwell and Marley, 1964), and no sedative drugs were prescribed while patients were taking part in the trials.

\section{EEG METHOD}

Five 15-second periods were recorded from electrodes over the posterior aspect of the non-dominant hemisphere. The details of recording and analysis of the traces are as previously described (Read et al, 1969), and allow calculation of the mean dominant frequency. 
BLOOD CHEMISTRY

Fasting blood ammonia was measured in arterial specimens by a modified method of Seligson and Hirahara (1957) in which a standard curve was constructed during each estimation. The percentage variation on a series of 20 standard estimations was plus or minus 16 at the $1.0 \mu \mathrm{g} / \mathrm{ml}$ level. Ammonia tolerance was estimated by measuring arterial ammonia levels at 45 and 90 minutes after an oral dose of 1 gram of ammonium chloride, administered in a fruit-flavoured drink. The effect of a single 30 mg dose of tranylcypromine one hour before an ammonia tolerance test was estimated and compared with the results of a similar ammonia tolerance test performed on the same patients without tranylcypromine. In two of these patients ammonia tolerance was retested following tranylcypromine, after the patients had been treated with neomycin in a dose of $1 \mathrm{~g}$ four times a day for three days. Fasting blood sugar levels were estimated before and after the course of tranylcypromine, and blood urea levels and electrolytes were also monitored in all the cirrhotic patients.

\section{Results}

EEG BEFORE AND AFTER TRANYLCYPROMINE Table I shows the change in the mean dominant frequency for the control and the liver disease groups. The mean change in the control group was a slowing of 0.33 cycles per second (standard deviation \pm 0.46 ), while in the group of liver patients it was 1.47 (standard deviation $\pm 1 \cdot 30$ ), which gives $P$ less than 0.05 using the WilcoxonWhite ranking test (sum of the ranks for the control

\begin{tabular}{|c|c|c|c|}
\hline $\begin{array}{l}\text { Liver } \\
\text { Patients }\end{array}$ & $\begin{array}{l}\text { Change in Mean } \\
\text { Dominant } \\
\text { Frequency }\end{array}$ & $\begin{array}{l}\text { Control } \\
\text { Subjects }\end{array}$ & $\begin{array}{l}\text { Change in Mean } \\
\text { Dominant } \\
\text { Frequency }\end{array}$ \\
\hline $\begin{array}{l}\text { Group } A \\
1 \\
2 \\
3 \\
4 \\
5\end{array}$ & $\begin{array}{l}\text { porto-systemic en } \\
-2 \cdot 00 \\
-2.30 \\
-4 \cdot 28 \\
-0.48 \\
-0.32\end{array}$ & $\begin{array}{l}\text { cephalopat } \\
1 \\
2 \\
3 \\
4 \\
5 \\
6 \\
7\end{array}$ & $\begin{array}{l}-0.67 \\
-0.60 \\
-0.32 \\
+0.59 \\
-0.28 \\
-0.79 \\
-0.25\end{array}$ \\
\hline \multicolumn{2}{|c|}{ Mean $-1.88 \mathrm{SD} \pm 1.60$} & \multicolumn{2}{|c|}{ Mean -0.33 SD \pm 0.46} \\
\hline $\begin{array}{l}\text { Group B } \\
6 \\
7 \\
8 \\
9 \\
10\end{array}$ & $\begin{array}{l}\text { previous portosyste } \\
+0.20 \\
-1.04 \\
-1.07 \\
-0.99 \\
-2.37\end{array}$ & mic enceph & \\
\hline \multicolumn{4}{|c|}{ Mean -1.05 SD \pm 0.91} \\
\hline \multicolumn{4}{|c|}{ Overall mean for subjects $(\mathrm{A}+\mathrm{B})-1 \cdot 47 \mathrm{SD} \pm 1 \cdot 30$} \\
\hline
\end{tabular}

Table I Effect of tranylcypromine on the EEG of patients with cirrhosis group 41.5 and for the patients 111.5). Marked changes in the EEG of a few patients precluded the investigation of further patients, which might well have overcome the weighting effect of these large standard deviations on the statistical analysis. Seven of the 10 patients showed an EEG slowing greater than $\mathbf{0 . 6}$ cycles per second, and in six of these it was more than 1 cycle per second. Variation greater than 0.6 cycles per second is considered outside the normal range of day-to-day variation for cirrhotic patients (Read, McCarthy, Ajdukiewicz, and Brown, 1968).

There was no clear difference in the response of patients who had a slow peak frequency before parnate, compared with those who did not. The change in mean dominant frequency of the liver patients who had previously exhibited encephalopathy (group A) was greater than those who had not (group B). The mean slowing in group A was 1.88 \pm 1.60 cycles per second, while in group $B$ it was $1.05 \pm 0.91$ cycles per second (for group A compared with the control group $t=1.924, P$ less than 0.05 ; for group B compared with the control group $t=$ $1 \cdot 289$, $P$ between $0 \cdot 15$ and $0 \cdot 10$ ).

\section{CLINICAL CHANGE}

Four of the patients with liver disease became very drowsy on this dose of tranylcypromine, while two other patients were moderately drowsy. The remaining four liver patients and all the control subjects appeared unaffected.

\section{BLOOD CHEMISTRY}

Fasting arterial ammonia levels before and after parnate were measured in three patients with cirrhosis and in two of the control group. There was a mean increase of $0.35 \mu \mathrm{g} / \mathrm{ml}$ in the patients compared with $0.14 \mu \mathrm{g} / \mathrm{ml}$ in the control group, and all patients showed some increase. In a further five patients with cirrhosis, ammonia tolerance was estimated before and after a single $30 \mathrm{mg}$ dose of parnate given orally one hour before the test commenced. These results are shown in Table II. In three patients at least one arterial ammonia level following parnate was significantly higher (greater than $0.6 \mu \mathrm{g} / \mathrm{ml}$ ) than the corresponding value obtained during tolerance tests not preceded by parnate. This difference was apparent at 45 minutes in one patient and at 90 minutes in the remaining two patients. Four days' treatment with neomycin before the ammonia tolerance test after $30 \mathrm{mg}$ of parnate did not significantly alter the increase produced by parnate.

No reduction in blood sugar levels nor alteration in blood urea or electrolytes could be found to account for the EEG changes quoted. 


\begin{tabular}{|c|c|c|c|}
\hline \multirow[t]{2}{*}{ Patient } & \multicolumn{3}{|c|}{ Ammonia Tolerance after } \\
\hline & $\begin{array}{l}1 \text { Gram } \\
\text { Ammonium } \\
\text { Chloride } \\
\left(\mathrm{NH}_{3} \text { levels }\right. \\
\text { in } \mu \mathrm{g} / \mathrm{ml})\end{array}$ & $\begin{array}{l}30 \text { mg Parnate } \\
\text { before } 1 \text { Gram } \\
\text { Ammonium } \\
\text { Chloride }\end{array}$ & $\begin{array}{l}\text { Neomycin } 1 \mathrm{Gram} \\
\text { qds for Three } \\
\text { Days and } 30 \mathrm{mg} \\
\text { Parnate before } \\
1 \text { Gram } \\
\text { Ammonium } \\
\text { Chloride }\end{array}$ \\
\hline 1 & $\begin{array}{l}1.70 \\
2.30 \\
1.71\end{array}$ & $\begin{array}{l}1.90 \\
2.29 \\
2.34\end{array}$ & $\begin{array}{l}1.54 \\
2.47 \\
2.01\end{array}$ \\
\hline 2 & $\begin{array}{l}1.00 \\
1.22 \\
0.81\end{array}$ & $\begin{array}{l}0.98 \\
0.46 \\
1.74\end{array}$ & $\begin{array}{l}0.75 \\
1.02 \\
0.70\end{array}$ \\
\hline 3 & $\begin{array}{l}0.97 \\
0.84 \\
0.62\end{array}$ & $\begin{array}{l}0.50 \\
0.88 \\
0.57\end{array}$ & $\begin{array}{l}0.85 \\
0.45 \\
0.77\end{array}$ \\
\hline 4 & $\begin{array}{l}2 \cdot 44 \\
2 \cdot 64 \\
2 \cdot 14\end{array}$ & $\begin{array}{l}2 \cdot 25 \\
2 \cdot 35 \\
3 \cdot 52\end{array}$ & \\
\hline 5 & $\begin{array}{l}0.90 \\
1.24 \\
1.21\end{array}$ & $\begin{array}{l}0.94 \\
1.56 \\
0.83\end{array}$ & \\
\hline
\end{tabular}

Table II Ammonia tolerance ${ }^{1}$

${ }^{1}$ Ammonia levels were recorded on each occasion before and at 45 and 90 minutes after the ammonium chloride.

EEG BEFORE AND AFTER AMITRIPTYLINE The effect of amitriptyline on the EEG of patients with cirrhosis was unremarkable. There was no significant difference between the patients and the control group, as the average change in the mean dominant frequency among the cirrhotic group was 0.27 cycles per second $\pm 0 \cdot 41$, while in the control group it was 0.17 cycles per second \pm 0.37 (P greater than 0.1 using the Wilcoxon-White ranking test, the sum of the ranks being 132 and 171 respectively). In one patient the maan dominant frequency was slowed by 1.25 cycles per second, one patient showed an EEG slowing of 0.6 cycles per second, but in no other patient or control was the change greater than 0.6 cycles per second.

A further five patients with cirrhosis received 25 $\mathrm{mg}$ of amitriptyline three times a day for one week, and the mean change in the dominant frequency at the end of this time was a slowing of 0.62 cycles per second. These results are shown in Table III. One of

\begin{tabular}{lccl}
\hline Patient & $\begin{array}{l}\text { Initial Mean } \\
\text { Dominant } \\
\text { Frequency }\end{array}$ & $\begin{array}{l}\text { Final Mean } \\
\text { Dominant } \\
\text { Frequency }\end{array}$ & $\begin{array}{l}\text { Change in Mean } \\
\text { Dominant } \\
\text { Frequency }\end{array}$ \\
\hline 1 & 8.79 & $8 \cdot 14$ & -0.65 \\
2 & 7.92 & $8 \cdot 71$ & +0.79 \\
3 & 9.49 & 9.32 & -0.17 \\
4 & 11.74 & $11 \cdot 14$ & -0.60 \\
5 & 6.59 & 4.10 & -2.49 \\
\multicolumn{2}{l}{ Mean slowing } & -0.62 SD \pm 1.93 & \\
\hline
\end{tabular}

Table III Effect of amitriptyline in a dose of $25 \mathrm{mg}$ three times a day for one week these patients, who had a slow EEG record initially, slowed a further 2.49 cycles per second; two patients showed EEG slowing of 0.65 cycles and 0.60 cycles respectively; and the remaining two patients did not show significant change. No change in the blood sugar, urea, or electrolytes could be found to account for the marked EEG change in one patient, which persisted for at least two weeks subsequently, when no amitriptyline was being administered. It was felt that the explanation was one of an unrelated clinical deterioration coinciding with the onset of the study.

\section{CLINICAL CHANGES}

No patient exhibited undue drowsiness or other side effects during the short course of amitriptyline, although slight drowsiness, without an associated EEG change, was reported by four patients. During the week on amitriptyline one patient was noted to be intermittently slightly drowsy, and this was associated with an EEG slowing of 2 cycles per second.

BLOOD AMMONIA

Fasting arterial ammonia estimations were made in seven patients before and after $60 \mathrm{mg}$ of amitriptyline. Two patients had increases of greater than 0.40 $\mu \mathrm{g} / \mathrm{ml}$ although none had changes greater than 0.6 $\mu \mathrm{g} / \mathrm{ml}$. In one this change in ammonia level was associated with an EEG slowing of 1.25 cycles per second. The arterial ammonia level was decreased in three patients, although again this change was not greater than $0.6 \mu \mathrm{g} / \mathrm{ml}$. Arterial ammonia estimations before and after a week's therapy were made in two patients, and in one there was an increase of 0.84 $\mu \mathrm{g} / \mathrm{ml}$ which was associated with an EEG slowing of $2 \cdot 49$ cycles per second.

\section{Discussion}

The antidepressant drug tranylcypromine (Parnate) is a monoamine-oxidase inhibitor, which is structurally similar to amphetamine, is efficiently absorbed by the gastrointestinal tract, and appears to exert its pharmacological effects more quickly than the hydrazine derivatives (Shepherd and Lader, 1968). Slowing of the alpha activity in the EEG of depressed patients receiving a therapeutic dose of tranylcypromine has been reported, but when given to normal subjects in single doses of $20 \mathrm{mg}$ it was found to exert no detectable effect for up to six hours after administration (Goldstein, Murphree, and Pfeiffer, 1963).

Amitriptyline is a dibenzocyclodeheptadiene, loosely classed with the tricyclic antidepressant imipramine. It resembles the phenothiazines, and, like these, is also rapidly absorbed from the gastrointestinal tract. The subsequent major metabolic 
pathways consist of demethylation, N-oxidation, and hydroxylation, followed by conjugation with glucuronic acid. In a series of 44 subjects with depression, only two patients developed 'abnormal' records while on a therapeutic dose of amitriptyline (Winfield and Aivazion, 1962). In a series of nine patients who developed epilepsy while receiving amitriptyline only two showed any EEG slowing (Dallos and Heathfield, 1969).

Amitriptyline is a widely used antidepressant, but monoamine oxidase inhibitors have become less popular because of their occasionally serious side effects. The treatment of depression by drugs in patients with liver disease is difficult because of increased drug sensitivity. Thus the possibility of an associated beneficial effect due to monoamine oxidase inhibitors prompted us to include one in the present study. In 1958 Dawson and Sherlock reported that Marsilid lowered the blood ammonia levels in cirrhotic patients, but they were unable to detect any obvious clinical improvement, and one patient showed clinical deterioration. Our results not only confirm this, but also show that noticeable clinical and EEG deterioration is produced in the majority of such patients. The changes described in the present study were most marked when there was a history of previous hepatic encephalopathy. Although the difference between the EEG slowing produced in the liver patients compared with the control subjects only reached the 0.05 level of significance, the degree of slowing which was produced in a few patients prevented continuation of the study with a larger number of participants. For the same reason the dose of amitriptyline was initially kept below the therapeutic level, and was only increased when it was realized that for this drug there was a greater margin of safety. We were not able to confirm the reported findings of a lowered blood ammonia level in the few patients tested, nor did tranylcypromine produce any consistent change in ammonia tolerance following an ammonia load. These results are similar to those produced by chlorpromazine (Read et al, 1969) with decreased ammonia tolerance and EEG slowing, but differ slightly, in that there was no apparent differential response between the patients with a pretreatment peak frequency in the normal alpha range (8-13 cycles per second) and those whose initial peak frequency was slower.

In marked contrast to the effects produced by tranylcypromine, the EEG and clinical changes following both short and longer courses of amitriptyline showed no significant difference from the control group. There were, however, four exceptions: one, a patient who received the short, low-dose regime, and three who received a week's course of a therapeutic dose. One of the latter could have been due to a coincidental, but unrelated clinical deterioration, as it persisted for at least two weeks subsequently, but no such explanation can be offered for the former patients. Arterial ammonia levels following amitriptyline were slightly increased in two patients, although not in the patient who showed the greatest EEG change.

It is of some interest to speculate on the possible mechanisms involved in the changes reported in the present study, and to consider whether they represent changes similar to those which occur spontaneously in hepatic encephalopathy. It is certainly true that both the drug-induced and spontaneously occurring states resemble one another, in that both produce clinical signs of altered consciousness, and an increase in the slow activity recorded in the EEG. Although there is conflicting evidence relating to blood ammonia and hepatic coma, these changes might be brought about by an increase in, or a potentiation of, the toxic effects of an already increased blood ammonia level. Another explanation could be an increase in the blood levels of certain amines, for example, methionine (Phear, Ruebner, Sherlock, and Summerskill, 1956) or serotonin (Marrazzi and Hart, 1955), normally present in small amounts, or to a potentiation of their action by tranylcypromine. Alternatively monoamine-oxidase inhibition might disturb the normal balance of protein metabolism to give rise to potentially toxic abnormal amines. Other possibilities include $(a)$ the accumulation of 'false neurochemical transmitters' (Fischer and Baldessarini, 1971), and high blood levels of beta-phenylethylamine have been reported in patients with liver failure (Asatoor and Kerr, 1961); or $(b)$ undue sensitivity to direct, central actions of both drugs.

Our findings indicate that patients with cirrhosis are likely to exhibit marked sensitivity to the monoamine oxidase inhibitor tranylcypromine, and presumably to other related drugs of this type, and that this is a particular risk if there is a history of previous hepatic encephalopathy. Amitriptyline appears to exert less severe effects, but the possibility of undue sensitivity remains, and caution should be exercised. These findings do not take into account the altered metabolism of these drugs which may occur as a result of hepatic disease but only serve to emphasize the nature of their side effects.

We are grateful to Dr J. R. Clamp, Dr J. Morris, Miss J. Ford, and the late Miss M. Hendy for their help in this study.

\section{References}

Asatoor, A. M., and Kerr, D. N. S. (1961). Amines in blood and urine in relation to liver disease. Clin. chim. Acta, 6, 149-156. 
Blackwell, B., and Marley, E. (1964). Interaction between cheese and monoamine oxidase inhibitors in rats and cats. Lancet, 1, 530 531.

Dallos, V., and Heathfield, K. (1969). Iatrogenic epilepsy due to antidepressant drugs. Brit. med. J., 4, 80-82.

Dawson, A. M., and Sherlock, S. (1958). The effect of the amine oxidase inhibitor marsilid on ammonium metabolism in liver disease. Clin. Sci., 17, 587-595.

Fischer, J. E., and Baldessarini, R. J. (1971). False neurotransmitters and hepatic failure. Lancet, $2,75-80$.

Goldstein, L., Murphree, H. B., and Pfeiffer, C. C. (1963). Quantitative electro-encephalography in man as a measure of CNS stimulation. Ann. N.Y. Acad. Sci., 107, 1045-1056.

Laidlaw, J., Read, A. E., and Sherlock, S. (1961). Morphine tolerance in hepatic cirrhosis. Gastroenterology, 40, 389-396.

Marrazzi, A. S., and Hart, E. R. (1955). Relationship of hallucinogens to adrenergic cerebral neurohumors. Science, 121, 365 367.
Phear, E. A., Ruebner, B., Sherlock, S., and Summersill, W. H. J. (1956). Methionine toxicity in liver disease and its prevention by chlortetracycline. Clin. Sci., 15, 93-117.

Read, A. E., Laidlaw, J., and McCarthy, C. F. (1969). Effects of chlorpromazine in patients with hepatic disease. Brit. med. J., 3, 497-499.

Read A. E., McCarthy, C. F., Ajdukiewicz, A. B., and Brown, G. J. A. (1968). Encephalopathy after portacaval anastomosis. Lancet. 2, 999-1001.

Seligson, D., and Hirahara, K. (1957). The measurement of ammonia in whole blood erythrocytes and plasma. J. Lab. clin. Med. 49, 962-974.

Shepherd, M., Lader, M., and Rodnight, R. (1968). Clinical Psychopharmacology, p. 135. English Universities Press, London.

Sherlock, S. (1964). Jaundice due to drugs. Proc. roy. Soc. Med., 57, 881-886.

Winfield, D. L., and Aivazian, G. H. (1962). Effect of amitriptyline on the E.E.G. Dis. nerv. Syst., 23, 517-518. 